\title{
Fretting corrosion tests on orthopedic plates and screws made of ASTM F138 stainless steel
}

\author{
Claudio Teodoro dos Santos*, Cássio Barbosa, Maurício de Jesus Monteiro, Ibrahim de Cerqueira Abud, \\ Ieda Maria Vieira Caminha, Carlos Rodrigo de Mello Roesler
}

\begin{abstract}
Introduction: Although there has been significant progress in the design of implants for osteosynthesis, the occurrence of failures in these medical devices are still frequent. These implants are prone to suffer from fretting corrosion due to micromotion that takes place between the screw heads and plate holes. Consequently, fretting corrosion has been the subject of research in order to understand its influence on the structural integrity of osteosynthesis implants. The aim of this paper is to correlate the surface finish characteristics of bone plate-screw systems with fretting corrosion. Methods: The surface finish (machined and polished) of five specimens taken from three commercial dynamic compression plates (DCP) were evaluated. For testing, the specimens were fixed with bone screws, immersed in a solution of $0.90 \% \mathrm{NaCl}$ and subjected to a rocking motion with an amplitude of $1.70 \mathrm{~mm}$ and frequency of $1.0 \mathrm{~Hz}$ for $1.0 \times 10^{6}$ cycles, according to the ASTM F897 standard. Both, plate and screws were manufactured in Brazil with ASTM F138 stainless steel. Results: Flaws on the hole countersink area and on the screw thread of some specimens were identified stereoscopically. At the end of the test all the specimens showed evidence of fretting corrosion with an average metal loss of $4.80 \mathrm{mg} / \mathrm{million}$ cycles. Conclusion: An inadequate surface finish in some areas of the plates and screws may have favored the incidence of damage to the passive film, accelerating the fretting corrosion at the interfaces between the plate hole countersink and the screw head.
\end{abstract}

Keywords: Osteosynthesis, DCP, Bone plate, Screw, Fretting corrosion, Stainless steel.

\section{Introduction}

Over the past five decades there have been significant advances in design and development of orthopedic implants, which were successfully applied in surgeries of hip, shoulder, knee, spine and fixation of bone fractures (osteosynthesis). However, failures of these implants are not uncommon and fretting corrosion is a well know degradation mechanism observed in bone plate-screw systems. This is a critical process because corrosion increases the possibilities of metal fatigue and the release of corrosion products into the tissues surrounding the implant may have adverse effects on local tissues or have systemic effects. The concentration of metal ions in body fluids and tissues due to corrosion can reach toxic levels and cause cancer, genetic damage and inflammatory responses (Sargeant and Goswami, 2007).

Implants with metallic materials such as stainless steel, titanium and its alloys as well as Co-Cr-Mo alloys are self-protected against corrosion by the spontaneous formation of a thin passive oxide film. This film acts as a highly protective barrier between the metal surface and the aggressive biological environment, preventing general corrosion of the implant. However,

*e-mail: claudio.santos@int.gov.br

Received: 15 January 2015 / Accepted: 19 May 2015 the fretting due to an oscillatory motion between the contact surfaces of the plate-screw system used to stabilize a bone fracture causes a localized breakdown of this passive film, leading to localized corrosion at the interfaces (Virtanen et al., 2008).

Fretting corrosion is therefore a combined action of mechanical wear, which destroys the passive film, and a corrosive attack on the metal surface (Virtanen et al., 2008). This type of corrosion is generally influenced by the surface finish and by the presence of inhomogeneities or discontinuities in the material itself (Hoeppner and Chandrasekaran, 1994). A continuous process of removal-reformation of the passive film leads to the release of metal ions or particles that can cause adverse local reactions such as inflammation of tissues. Furthermore, fretting corrosion is also seen as a generator of stress concentration points that may cause crack nucleation and premature failure of the implant (Hoeppner and Chandrasekaran, 1994). Surface analyses of the implants and their metal particles can provide important information regarding the magnitude and mechanism of fretting corrosion (Billi et al., 2009). 
Orthopedic bone plates are used for osteosynthesis and are screwed onto the bone. The plate models most commonly used mainly differ in the screw design (Miller and Goswami, 2007; MacLeod et al., 2015). The dynamic compression plate (DCP) is a plate in which the screws must be pressed or tightened into the countersunk holes, which means the plate is compressed directly onto the bone (Kanchanomai et al., 2008). In the DCP system a high level load is transmitted from the screws through the bone-plate interface (Kanchanomai et al., 2008). Thus, the fracture stability is achieved by axial compression of bone fragments. However, the compression forces between the bone surface and plate may cause vascular damage to undersurface bone tissue, which results in unfavorable conditions for bone healing under the plate (Kanchanomai et al., 2008). The subsequent design, the limited-contact dynamic compression plate (LC-DCP) is a modified DCP developed to preserve the blood supply by reducing the contact with the bone by approximately $50 \%$ (Miller and Goswami, 2007; Uhthoff et al., 2006). More recently, the locking compression plate (LCP) has been introduced. Locked plates use locking screws that have a threaded head enabling the screw to fasten into the plate as well as into the bone (MacLeod et al., 2015). Therefore, as the screws lock onto the plate, the LCP is not pressed directly onto the bone, thus eliminating the need for contact between the plate and bone. This new plate design intended to reduce bone plate contact to the point where it was essentially negligible (Uhthoff et al., 2006). The disadvantage of these original locking plates is that screws could only be placed perpendicular to the plate. Thus, another type of LCP, which combines the conventional hole with the threaded hole, was also developed. The combination hole of the LCP is designed so that it can house either a conventional screw or a locking head screw in order to allow for the maximum number of combinations and options. As a result, the LCP can be applied as a compression plate by using the conventional holes, as a locked plate by using the threaded holes, or as a combination/hybrid plate which incorporates both types of holes (Miller and Goswami, 2007).

Based on recent research that has documented the beneficial influence of a range of axial micromotions for the fracture healing, other plates were developed, such as the axially compressible plate (ACP), in which the insertion of cushions made from polymeric bioresorbable material between the screw shank and the wall of the oval plate holes allows true dynamic compression (micromotion) at the fracture site. The inserts reduce the load transmission during the bone healing process and increase to a point of completely eliminating load sharing by the plate
(Uhthoff et al., 2006). However, this new type of plate needs to be improved and several studies are being conducted to make it fully functional.

While the LCP is becoming increasingly popular for complex fractures, the DCP remains the standard choice (MacLeod et al., 2015). In fact, this choice depends on the quality of the bone and fracture pattern. Some studies have suggested that the DCP is more suitable for younger or stronger bones and simple fractures (MacLeod et al., 2015).

As these implants have many metal-metal interfaces, the concern regarding fretting corrosion is even greater. Generally, the contact surface between the underside of the screw head and the countersink of the plate hole creates conditions for fretting corrosion and the surface finish of these components may play a key role in the occurrence and magnitude of this type of corrosion. Thus, the main aim of the present study is to evaluate the influence of the surface finish on the fretting corrosion of commercial DCP plates and screws manufactured with ASTM F138 stainless steel (American..., 2013a), which is the standard choice adopted by the Brazilian National Health Service (SUS) due to its lower cost and good mechanical properties.

\section{Methods}

Three commercial dynamic compression plates (DCP) were used. Each plate had 6 oval holes $(4.50 \mathrm{~mm}$-width and $101.0 \mathrm{~mm}$-length) and their respective spherical cortical screws (4.50 mm-diameter and $38.0 \mathrm{~mm}$-length). All plates and all screws were taken from the same lot manufactured in Brazil with ASTM F138 austenitic stainless steel (American..., 2013a). The plates are machined and polished to obtain their surface finish.

The procedures for obtaining, preparing and testing the specimens were performed according to the ASTM F897 standard (American..., 2013b). These procedures are detailed in the block diagram of Figure 1, and the description of the sequence is presented below:

First, the plates and screws were cleaned with distilled water and neutral detergent to remove any grease or dirt. Then, the plates and screws were subjected to visual analysis to check the quality of surface finish and to identify the existence of any flaws or other imperfections that could influence the fretting corrosion test. After the visual inspection, macroscopic analyses were carried out with an Olympus stereoscope model SZX16 to qualify the surface finish.

Subsequently, the three bone plates were cut in order to provide a total of five test specimens $(n=5)$ with at least two holes each. Then, each specimen and 
its two screws (Figure 2) were weighed together on an analytical balance, with an accuracy of $0.01 \mathrm{mg}$.

For the test, each specimen was immersed in a beaker containing a solution of $0.90 \% \mathrm{NaCl}$ in distilled water. Before conducting the test, the $\mathrm{pH}$ of the solution was measured to guarantee a $\mathrm{pH}$ range of 6.5 to 7.5. The in vitro fretting corrosion test was carried out using the custom-made A3S equipment (Figure 3), which was manufactured in Brazil especially for studies concerning osteosynthesis plates and screws according to the test method described in the ASTM F897 standard (American..., 2013b). The A3S machine consists of an electromechanical actuator that simulates forces and motions of a bone fracture and allows us to perform up to five tests, simultaneously. This equipment induces a rocking motion in the longitudinal direction of the plate,

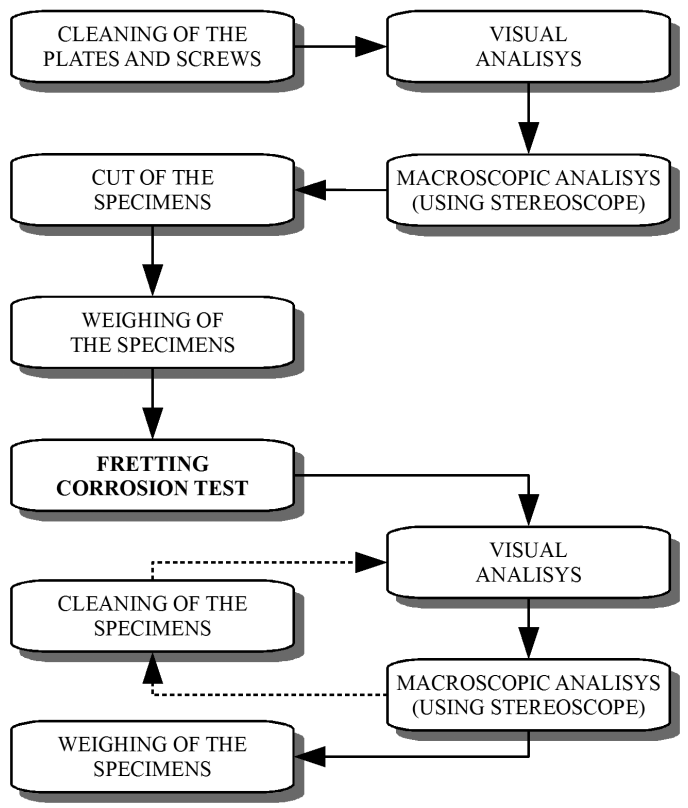

Figure 1. Sequence of preparation, testing and analysis of the specimens.

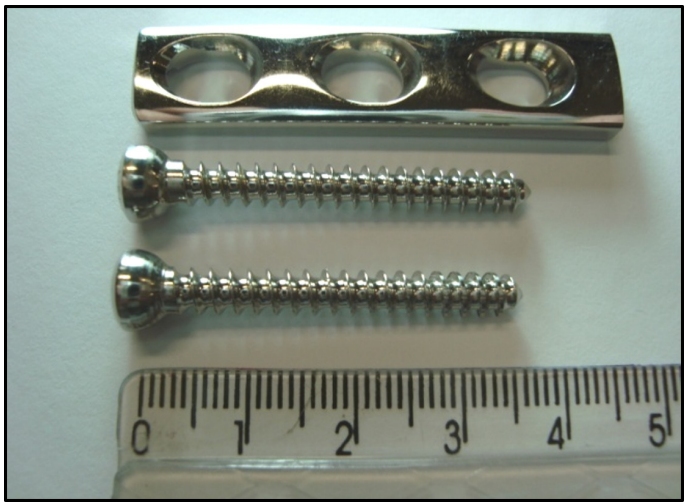

Figure 2. Specimens of plate and screws. resulting in a micromotion between the screw head and the countersink of the plate hole. The plate is fixed by screws passing through the holes, rubber spacers and plastic rods, as shown in Figure 3. The torque applied on the screws was controlled and equal to $0.60 \mathrm{~N} . \mathrm{m}$, which corresponds to an axial load of about $670.0 \mathrm{~N}$. Spacers are used to maintain an axial load on the screws and to permit the necessary axial displacements associated with the rocking motion of the screws, while at the same time preventing fatigue failure of the screws. The displacement amplitude was set at $1.70 \mathrm{~mm}$, with a motion frequency of $1.0 \mathrm{~Hz}$. The test was run continuously for $1.0 \times 10^{6}$ cycles (11 days) with five plate-screw specimens, simultaneously. In order to prevent the entry of any foreign particles into the solution during the test, the beakers were covered with a thin piece of flexible rubber, with two holes punched out to make a tight fit around the plastic rods.

After the test, each specimen was removed from the plastic bars and cleaned with neutral detergent and distilled water to remove any deposited corrosion residues. The amount of fretting corrosion was determined by measuring the total loss of mass from the metallic components. Thus the average loss of mass of the five specimens was determined.

Then, visual and stereoscopic analyses were done on the plates and screws for evidence of any fretting corrosion. The degree of corrosion was classified according to the Weinstein criterion (Weinstein et al., 1979).

\section{Results}

\section{Previous analysis of the surface finish of the plate-screw specimens}

Before the fretting corrosion test no flaws on the surface of the plates or screws were seen with the naked eye. However, flaws on the surface finish were seen

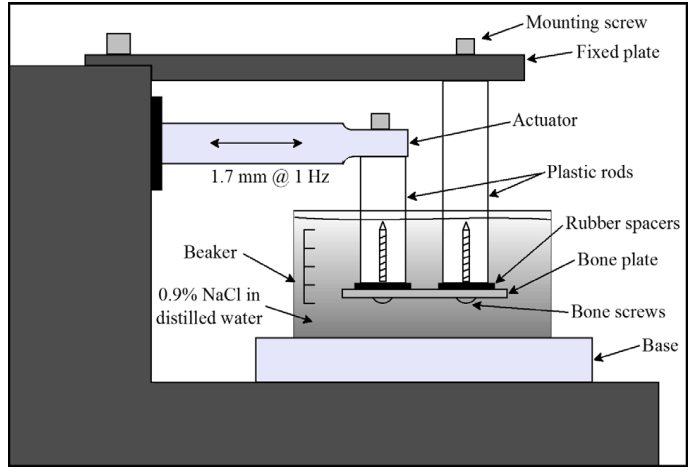

Figure 3. Schematic drawing of a specimen mounted on the fretting corrosion equipment. 
using the stereomicroscope at 10x magnification, both in the hole countersink area and on the screw thread of some specimens. Figure 4 shows a manufacturing flaw found on the plate hole.

\section{Analysis of fretting corrosion of the plate-screw specimens}

Figure 5 shows the characteristic of the plate hole countersink before and after the fretting corrosion test. The surface of the countersink hole that was in contact with the screw head during the test showed evidence of fretting corrosion, as indicated by adjacent regions of wear and corrosion caused by the relative motion between the surfaces of the components in the test solution. The arrows point to a pre-existing flaw in the surface finish that may have influenced this degradation. Mechanical failure did not occur in any of the specimens or screws until the test end (one million cycles), although corrosion and wear have been observed.

Figure 6 shows the characteristic of another plate hole after the fretting corrosion test, in this case, (a)

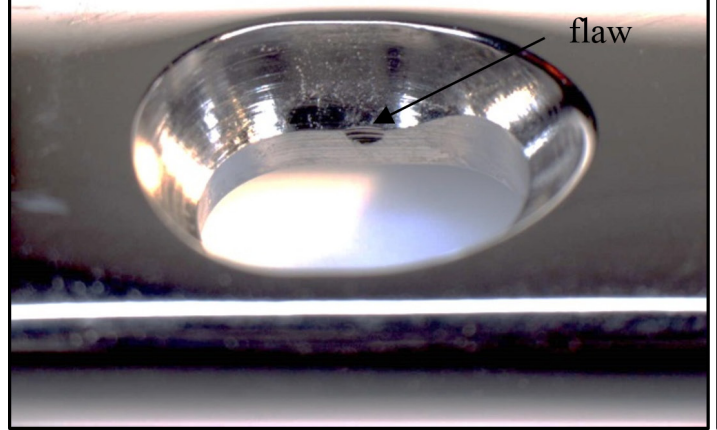

(b)

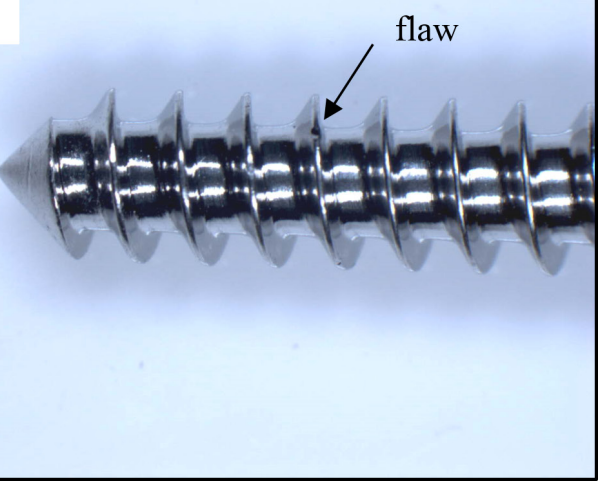

Figure 4. Surface finish flaws identified at (a) the plate hole countersink and at (b) the screw thread (10x).
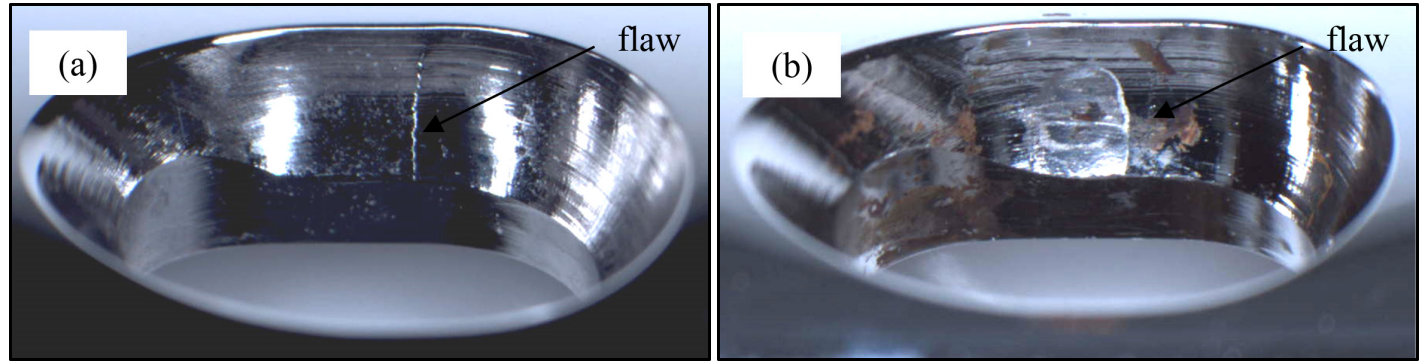

Figure 5. Plate hole (a) before and (b) after the fretting corrosion test (10x). Arrows indicate a surface finish flaw (line crossing the hole).
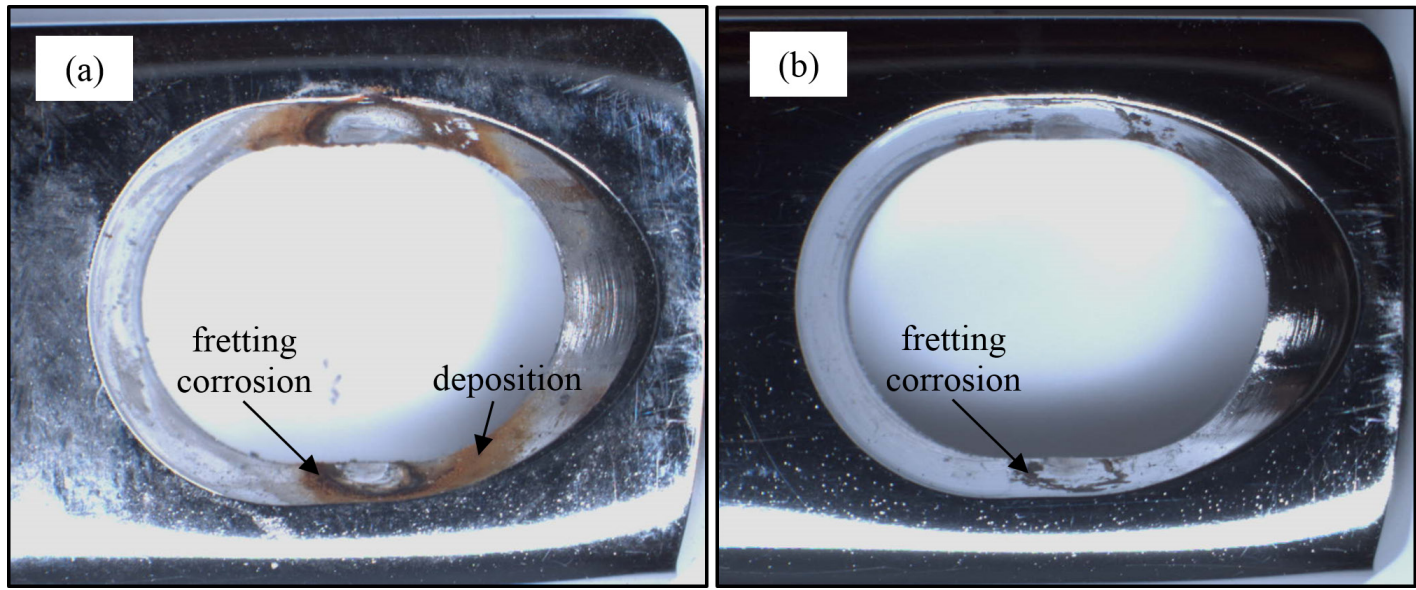

Figure 6. Plate hole after the fretting corrosion test, (a) before and (b) after cleaning the specimen (10x). Arrows indicate regions of deposit and corrosion, respectively. 


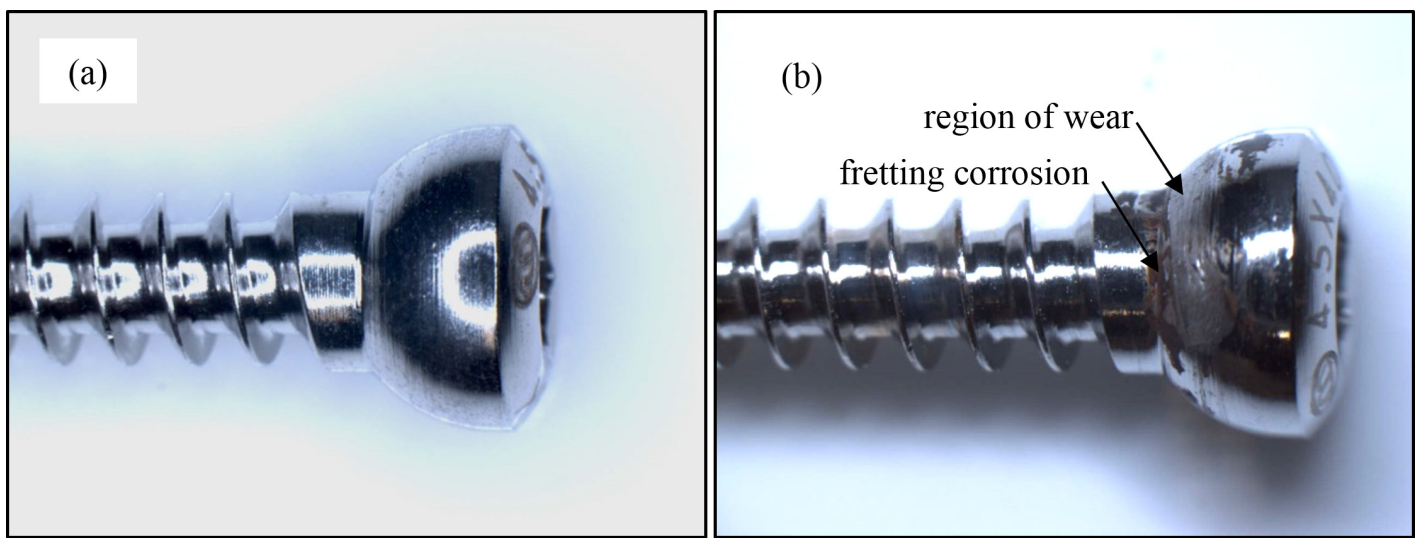

Figure 7. Screw head (a) before and (b) after the fretting corrosion test (10x). Arrows indicate the main region of wear.

before and after cleaning the specimen. In Figure 6a a deposit of corrosion products on the surface of the hole around the contact point of the screw can be seen. In Figure $6 \mathrm{~b}$ the corrosion occurred particularly in the region that formed an interface between the screw, the hole countersink and the saline solution, indicated by the degradation in the peripheral part of the region where the screw had contact with the plate hole.

Figure 7 shows the changes in the screw surface after the fretting corrosion test. Also the adjacent regions of mechanical wear and corrosion, which are indicative of the fretting corrosion mechanism, can be seen.

The fretting corrosion in the specimens here were classified as grade 1 (corrosion visible with the naked eye), according to the criterion of Weinstein et al. (1979).

The average loss of mass of the components was $4.80 \mathrm{mg} / \mathrm{million}$ cycles with a $\mathrm{pH}$ of 6.80 and a temperature of $25.6{ }^{\circ} \mathrm{C}$.

\section{Discussion}

The method used for the fretting corrosion test of bone-plate systems was based on the ASTM F897 standard (American..., 2013b). The system was immersed in a solution of $0.90 \% \mathrm{NaCl}$ in distilled water with a controlled $\mathrm{pH}$ of between 6.5 and 7.5. Considering the normal human body $\mathrm{pH}$ is about 7.4, the environment of body fluids can generally be simulated with this basic test solution (Hol et al., 2008). The chemical environment of blood plasma is highly aggressive for many metals and alloys, especially in the presence of a high concentration of chloride ions and their ability to induce localized corrosion. Other ions may also contribute to the corrosion process, but their effect is rarely considered due to their low concentration in the blood (Virtanen et al., 2008).
The test results demonstrated that the corrosion damage was restricted to a limited area, while the remaining areas only presented characteristics of wear or remained intact. This probably occurred because the fretting continually damaged the protective oxide film, exposing the alloy to direct contact with the aggressive environment in some regions. On the other hand, regions where the solution had no access, only the mechanical wear occurred as a consequence of the micromotion. Thus, the fretting promoted the removal of the oxide film and the release of oxide and metal fragments (debris) into the solution. In addition, the temporary local absence of the protective film put the alloy in direct contact with the solution, leading to its corrosion and/or repassivation, with the consequent release of ions into the solution. This hypothesis is based on observations made by Billi et al. (2009) in a study about wear debris in modular hip prosthesis and also based on the mechanism proposed by Gilbert and Jacobs (1997) to explain the fretting corrosion reaction. Kumar et al. (2010) have shown that fretting also leads to the temporary formation of a galvanic cell between the fretted areas (anodic) and the unworn areas (cathodic), which retards the repassivation process, increasing susceptibility to corrosion.

The surface flaws on the countersink located close to the contact point of the screw probably increased the local fretting, thus collaborating with the degradation mechanisms of the plate. In addition, surface flaws may have caused crevices, leading to preferential corrosion at these points. Fretting corrosion can occur in situations where there is a confined space or relative motion between the components (Brown et al., 1994). A better manufacturing process supplying higher quality surface finishes could minimize the amount of fretting corrosion.

There are few studies on the loss of mass associated with fretting corrosion in plate-screw type orthopedic implants. Therefore, the comparative analysis of the 
results obtained in this study is limited. Among such studies are those of Brown et al. $(1985 ; 1994)$ who performed similar studies of in vitro fretting corrosion with plates and screws made of $316 \mathrm{~L}$ stainless steel, Co-Ni-Cr-Mo (MP35N) and Ti-6Al-4V alloys. These authors reported a loss of mass of $2.9 \mathrm{mg}$ for $316 \mathrm{~L}$ stainless steel specimen immersed in a solution of $0.90 \% \mathrm{NaCl}$ in distilled water, using a fretting corrosion simulator, with a motion frequency of $1.0 \mathrm{~Hz}$ and for $0.60 \times 10^{6}$ cycles. Based on this result, it is possible to get a rough linear estimation of the loss of mass after one million cycles as $4.8 \mathrm{mg}$, i.e., the same value obtained in the present study, indicating that our result is potentially consistent with that reported by Brown and collaborators. In addition, these authors reported a lesser loss of mass for the specimen made of $\mathrm{Ni}-\mathrm{Co}-\mathrm{Cr}-\mathrm{Mo}$, which was $0.65 \mathrm{mg}$ and even less for the specimen made of Ti- $6 \mathrm{Al}-4 \mathrm{~V}$, which was $0.13 \mathrm{mg}$, both under the same test conditions.

Direct contact between the plate and screws are inherent in both traditional plates (DCP-type) and the newer plates (LCP-type), although the mode of contact is different for each plate. Since the contact surfaces of these components may be subjected to fretting due to the relative motion during load support, and fretting corrosion can occur on exposure to the environment. The DCP plate-screws analyzed in this study did not show plastic deformation or cracks after the fretting corrosion test. However, they presented corrosion products which could cause biological reactions or to accelerate the fatigue failure of the implant. In addition, the manufacturing process generated localized flaws on the finished surfaces, such as on the plate hole countersinks and screw threads. These flaws probably increased the contact stress and local fretting, damaging the barrier provided by the passive film of the implant and accelerating the fretting corrosion process. A better control in the manufacturing process could avoid the occurrence of surface flaws, thus decreasing the potential of these components to undergo fretting corrosion.

As surface flaws may increase fretting and accelerate corrosion, the results and observations of the present study contribute to quantify the metal loss of the bone plate-screws system by fretting corrosion. However, further studies varying the test parameters, such as number of cycles, frequency, type of test solution and torque on the screws are required to get a better understanding of the fretting corrosion mechanism.

Although fractures and skeletal deformity corrections are generally overcome within 2-3 months (approximately 150,000 to 250,000 cycles) when the bone healing process has progressed sufficiently so that the bone can provide the mechanical support and thus reduce the stresses in the bone plate, the tests carried out up to $1.0 \times 10^{6}$ load cycles. Therefore this can be seen as a conservative evaluation and its clinical relevance relies on the fact that once the corrosion process has begun it will continue as long as the system sustains cyclic loads.

\section{Acknowledgements}

The authors are grateful to Hugo Keide, Paulo Perdigão, Juliana Souza and Walter Ferreira Filho for their help in conducting the fretting corrosion test and for the acquisition of the stereoscopic images. We also thank CNPq, FAPESC and FAPERJ for their financial support.

\section{References}

American Society for Testing and Materials - ASTM. F13813a: Standard Specification for Wrought 18Chromium14Nickel-2.5Molybdenum Stainless Steel Bar and Wire for Surgical Implants. West Conshohocken: ASTM; 2013a.

American Society for Testing and Materials - ASTM. F89702: Standard test method for measuring fretting corrosion of osteosynthesis plates and screws. West Conshohocken: ASTM; 2013b.

Billi F, Benya P, Ebramzadeh E, Campbell P, Chan F, McKellop HA. Metal wear particles: what we know, what we do not know, and why. SAS Journal. 2009; 3(4):133-42. http://dx.doi.org/10.1016/j.esas.2009.11.006. PMid:25802639.

Brown SA, Merritt K, Payer JH, Kraay MJ. Fretting corrosion of orthopaedic implants. Pennington: The Electrochemical Society; 1994. p. 42-47.

Brown SA, Merritt K. Fretting corrosion of plates and screws: an in vitro test method. In: Fraker AC, Griffin CD, editors. Corrosion and degradation of implant materials. Philadelphia: American Society for Testing and Materials; 1985. p. 105-16. ASTM STP, 859

Gilbert JL, Jacobs JJ. The Mechanical and electrochemical processes associated with taper fretting crevice corrosion: a review, Modularity of Orthopedic Implants. ASTM Special Technical Publication. 1997; 1301:45-59.

Hoeppner DW, Chandrasekaran V. Fretting in orthopaedic implants: a review. Wear. 1994; 173(1-2):189-97. http:// dx.doi.org/10.1016/0043-1648(94)90272-0.

Kanchanomai C, Phiphobmongkol V, Muanjan P. Fatigue failure of an orthopedic implant: a locking compression plate. Engineering Failure Analysis. 2008; 15(5):521-30. http://dx.doi.org/10.1016/j.engfailanal.2007.04.001.

Kumar S, Narayanan TSNS, Raman SGS, Seshadri SK. Evaluation of fretting corrosion behavior of CP-Ti for orthopaedic implant applications. Tribology International. 2010; 43(7):1245-52. http://dx.doi.org/10.1016/j. triboint.2009.12.007.

MacLeod AR, Simpson AHRW, Pankaj P. Reasons why dynamic compression plates are inferior to locking plates in 
osteoporotic bone: a finite element explanation. Computer Methods in Biomechanics and Biomedical Engineering. 2015; 18(16):1818-25. http://dx.doi.org/10.1080/102558 42.2014.974580. PMid:25473732.

Miller DL, Goswami T. A review of locking compression plate biomechanics and their advantages as internal fixators in fracture healing. Clinical Biomechanics (Bristol, Avon). 2007; 22(10):1049-62. http://dx.doi.org/10.1016/j. clinbiomech.2007.08.004. PMid:17904257.

Sargeant A, Goswami T. Hip Implants - paper vi - ion concentration. Materials \& Design. 2007; 28(1):155-71. http://dx.doi.org/10.1016/j.matdes.2005.05.018.

Uhthoff HK, Poitras P, Backman DS. Internal plate fixation of fractures: short history and recent developments. Journal of Orthopaedic Science: Official Journal of the Japanese Orthopaedic Association. 2006; 11(2):118-26. http://dx.doi. org/10.1007/s00776-005-0984-7. PMid:16568382.

Virtanen S, Milosev I, Gomez-Barrena E, Trebse R, Salo J, Konttinen YT. Special modes of corrosion under physiological and simulated physiological conditions. Acta Biomaterialia. 2008; 4(3):468-76. http://dx.doi.org/10.1016/j. actbio.2007.12.003. PMid:18226986.

Weinstein AM, Spires WP, Klawitter JJ, Clemow AJT, Edmunds JO. Orthopedic implant retrieval and analysis study. In: Syrett BC, Acharya A, editors. Corrosion and degradation of implants materials. Philadelphia: American Society for Testing and Materials; 1979; p. 212-28. ASTM STP, 684.

\section{Authors}

Claudio Teodoro dos Santos ${ }^{1 *}$, Cássio Barbosa ${ }^{1}$, Maurício de Jesus Monteiro ${ }^{1}$, Ibrahim de Cerqueira Abud ${ }^{1}$, Ieda Maria Vieira Caminha ${ }^{1}$, Carlos Rodrigo de Mello Roesler ${ }^{2}$

${ }^{1}$ Instituto Nacional de Tecnologia - INT, Av. Venezuela, 82, CEP 20.081-312, Rio de Janeiro, RJ, Brazil.

${ }^{2}$ Laboratório de Engenharia BioMecânica - LEBm, Hospital Universitário, Universidade Federal de Santa Catarina - UFSC, Florianópolis, SC, Brazil. 